\title{
Original
}

\section{Plasma ACE activity after aerobic exercise training is related to sleep in migraine patients: A secondary, per protocol analysis} Atividade da ECA após treinamento físico aeróbio é correlacionada com sono em pacientes com migrânea: uma análise secundária por protocolo

\section{Arão Belitardo Oliveira ${ }^{1,2}$ (D) Bruna Visniauskas³ (iD) Jair Ribeiro Chagas ${ }^{4}$ (i) Mario Peres ${ }^{2,5}$}

${ }^{1}$ Universidade Federal de São Paulo, Neurologia e Neurocirurgia, São Paulo, São Paulo, Brazil. ${ }^{2}$ Hospital Israelita Alber Einstein, Instituto do Cerebro, São Paulo, São Paulo, Brazil. ${ }^{3}$ Tulane University School of Medicine, Department of Physiology, New Orleans, Louisiana, Estados Unidos. ${ }^{4}$ Universi-

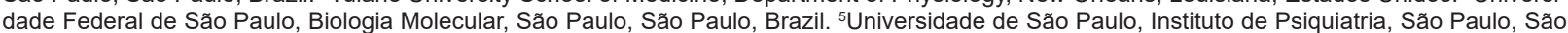
Paulo, Brazil.

\section{$\triangle$}

Arão Belitardo Oliveira araoliva@gmail.com

Edited by:

Marcelo Moraes Valença

\section{Keywords:}

Physical Activity

Exercise Therapy

Angiotensin-Converting Enzyme

Chronic Pain

Headaches Disorders

Migraine

Sleep

Palavras-chave:

Atividade Física

Terapia por Exercício

Enzima conversora da angiotensina

Dor crônica

Cefaleias

Migrânea

Sono

\begin{abstract}
Angiotensin converting enzyme-1 (ACE) has been implicated in sleep regulation and nociception. In a secondary, per-protocol analysis, we investigated the effect of a 12-week aerobic exercise program on plasma ACE activity (primary outcome variable), migraine clinical outcomes, and psychometric scores between migraine and control, non-headache participants. Fifty-nine participants (migraine: $n=31$ and control: $\mathrm{n}=28$ ) gave signed consent form and were per-protocol analyzed. At baseline, there were no differences between groups for ACE activity. After the intervention period, the ACE activity increased in the migraine exercise group compared to control waitlist group [mean difference $(95 \% \mathrm{Cl})=33.8 \mathrm{nM} \cdot \mathrm{min}^{-1} \cdot \mathrm{mg}^{-1}(1.0$, $66.5), p=0.02$ ]. Among patients, the migraine exercise group showed greater numeric reduction in the number of sleep deprivation-triggered attacks compared to migraine waitlist group (-21 vs -8, respectively), and lower insomnia scores [mean difference $(95 \% \mathrm{Cl})=-0.625(-996,-254), \mathrm{p}=0.001]$. There was an inverse correlation between BECK-II insomnia domain scores and ACE activity $(r=-0.53, p=0.035)$. This study suggests that aerobic exercise training increases plasma ACE activity with possible implication on sleep regulation in migraine patients.
\end{abstract}

\section{Resumo}

A enzima conversora de angiotensina-1 (ECA) está implicada na regulação do sono e nocicepção. Em uma análise secundária por protocolo, objetivamos investigar o efeito de um programa de exercícios aeróbicos de 12 semanas na atividade da ECA plasmática (variável de resposta primária), variáveis clínicas e escores psicométricos entre participantes com migrânea e controle sem nenhum tipo de cefaleia. Cinquenta e nove participantes (enxaqueca: $n=31$ e controle: $n=28$ ) assinaram o termo de consentimento e foram analisados por protocolo. No período basal, não houve diferenças entre os grupos para a atividade da ECA. Após o período de intervenção, a atividade da ECA aumentou no grupo de exercícios com migrânea em comparação ao grupo de lista de espera de controle [diferença média (IC95\%) = 33,8 nM.min - 1 .mg - 1 $(1,0,66,5), p=0,02]$. Entre os pacientes, o grupo exercício mostrou maior redução numérica no número de ataques desencadeados por privação do sono em comparação com o grupo controle $(-21$ vs -8, respectivamente) e menores escores médios do domínio de insônia BECK-II [diferença média $(95 \% \mathrm{Cl})=-0,625$ $(-996,-254), p=0,001]$. Houve uma correlação inversa entre os escores de insônia e a atividade da ECA $(r=-0,53, p=0,035)$. Este estudo sugere que o exercício aeróbico regular aumenta a atividade da ECA no plasma com possível implicação na regulação do sono em pacientes com migrânea. 


\section{Introduction}

A erobic exercise training exerts prophylactic effects on migrai$n e^{1,2}$, and also promotes anxiolytic effects ${ }^{2}$ in this population. In spite of ample theoretical explanations for the preventive effects of exercise for migraine, the mechanisms underlying the therapeutic effects of aerobic exercise are still elusive.

Angiotensin-l-converting enzyme (ACE), a key protease of the renin angiotensin system (RAS), has been implicated in migraine pathophysiology by mechanisms still not understood ${ }^{3-5}$. ACE cleavages angiotensin-I into angiotensin-II (Angll), a potent vasoconstrictor which also orchestrates several physiological adjustments and adaptations in response to acute and chronic physical exercise ${ }^{6,7}$. The RAS is operative in stress sensitivity ${ }^{8}$ and sleep regulation", which are associated with migraine triggers ${ }^{10}$, and pain perception ${ }^{11}$. Thus, it is plausible to hypothesize the participation of this signaling system in the clinical response to regular aerobic exercise and the mechanisms related to common migraine triggers such as stress and sleep deprivation.

Considering the participation of ACE in other pathological states such as hypertension, heart failure, diabetes, and chronic kidney disease, and the health-related effects of aerobic exercise training counterpointing an exaggerated RAS tone observed in these conditions $s^{6,7}$, we hypothesized that migraine patients would exhibit higher plasma ACE activity and that aerobic exercise training would reduce plasma ACE activity in this population. Secondarily, we hypothesized that there would be correlations between changes in ACE and clinical outcomes, as well as with migrainerelated triggers and psychometric variables associated with ACE physiology.

Therefore, we compared plasma ACE activity between patients with migraine and healthy, nonheadache individuals, and investigate the influence of aerobic exercise training on this protease activity. We further exploited possible correlations between exercise traininginduced changes in ACE activity, psychometric scores (i.e., stress, sleep, etc.) and clinical outcomes (e.g., days with headaches and migraine triggers). These data were preliminary presented at the 5th European Headache and Migraine Trust International Congress, held in Glasgow in September 2016.

\section{Methods}

\section{Study Design}

This is secondary, per-protocol analysis of a randomized controlled trial aimed at testing the effect of a 12-week aerobic exercise program on clinical outcomes ${ }^{2}$. We analysed the plasma ACE activities, clinical outcomes and psychometric scores, as well as tested the correlations between these variables. Participants were randomly assigned to receive intervention with aerobic exercise training (exercise groups) or enter a waitlist (waitlist groups). Simple randomization (1:1) was performed using an online number generation software.
Study's protocol was composed by 7 clinical visits scheduled every 4 weeks, including the screening, neurological examination, and delivery of headache diaries (Visit 0), and revaluations for checking the headache diagnosis and diaries (visits 1-6). The baseline period was set as the 4-week period between visits 0 and 1 . Blood sampling and psychometric interview were scheduled in the samevisit, between visits 1 and 2, and were followed by the 12week intervention period. The last 4 weeks of the intervention period (between visits 5-6) was set as "post-intervention" period for clinical analyses. Test-retest visits for blood collection and psychometric interviews were scheduled in the same order. All women were at the follicular phase of the menstrual cycle at the blood sampling visit. Retest visits for blood sampling were performed between 2-5 days after the last exercise session, or $48 \mathrm{~h}$ after the last exercise session within the same phase of the menstrual cycle as undertaken at baseline. For all test-retest visits, participants were instructed to breakfast regularly, but to abstain from coffee. All patients were within the interictal period during all test-retest measurements.

The study's protocol complied with the 1964 Helsinki declaration on human research and was approved by the UNIFESP's Research Ethical Committee, registered under \#081511, and all participants gave written informed consent. This study was also registered in the National Institute of Health (www.ClinicalTrials.gov) under \#NCT01972607.

\section{Participants}

We recruited patients from the Headache Unit of Hospital São Paulo and a headache tertiary clinic, and healthy individuals from the local community through printed and electronic media advertisements between March 2012 and March 2015. Participants were screened and evaluated by a neurologist. In this analysis, we added 9 participants to the primary analysis sample, 7 chronic migraine patients and 2 healthy controls.

Inclusion criteria were: individuals of both sex, aged between 18 and 65 years, non-headache individuals (defined as controls), and patients with episodic and chronic migraine with/without aura, according to the $2^{\text {nd }}$ version of the International Classification of Headache Disorders ${ }^{12}$. Patients should not be under any prophylactic treatment for migraine (except for using abortive medication during attacks) or taking any other prescribed drug or dietary supplement. Participants should be physically inactive $(\leq 1$ day/week of leisuretime physical activity the previous 12 months). Exclusion criteria were: starting any non-pharmacological or pharmacological treatment during the study period, or presenting any other disease such as cardiovascular, pulmonary, metabolic, musculoskeletal, rheumatic, or neurological disorder, including another primary or secondary headache; smoking, alcohol, or drug abuse, and disagreement to continue the protocol.

\section{Intervention}

All exercise sessions were supervised by experienced exercise 
physiologists. The 12- week program of aerobic exercise training was conducted at the Center for Studies in Psychobiology and Exercise, São Paulo, Brazil. It comprised 40-minute sessions of walking or jogging on treadmill, performed 3 times per week at treadmill speed $\left(\mathrm{m} \cdot \mathrm{min}^{-1}\right)$, heart rate, and rate of perceived effort corresponding to the ventilatory threshold. The ventilatory threshold was determined during maximal cardiopulmonary exercise test as described in a previous study ${ }^{2}$.

\section{Headache Diary}

The headache diary retrieved data on days with migraines, migraine frequency, number of acute medication used, and commonly reported migraine attack triggers: stress/irritability, oversleep, sleep deprivation, alcohol, fasting, odorants and photic stimuli, foods, menstruation, fatigue, weather, neck/back pain, or nonidentifiable.

\section{Psychometric Questionnaire}

Participants filled the psychometric questionnaires at the Psychobiology Department before the blood collection. Depression scores were assessed by Beck Depression Inventory-II (BECK-II). Beck-II questionnaire has been validated and translated into Brazilian Portuguese.

\section{ACE Activity Assays}

Blood samples were collected between 8:00AM and 10:00AM at the Psychobiology Department after questionnaire filling, by venepuncture of the antecubital vein in cooled heparinized vacutainers (BD Vacutainer ${ }^{\circ}$, Franking Lakes, NY, USA). Samples were immediately centrifuged for 10 minutes at a $3,400 \mathrm{~g}$ at $4{ }^{\circ} \mathrm{C}$. Plasma was separated, aliquoted in $2 \mathrm{~mL}$ vials, and stored at $-80^{\circ} \mathrm{C}$ until analysis. All samples were analysed within 6 months after blood collection.

ACE activity was determined spectrofluorimetrically using fluorescence resonance energy transfer (FRET) peptides. The FRET peptides Abz-FRK(Dnp)P-OH (Aminotech Pesquisa e Desenvolvimento, Brazil) was used, as described by Carmona ef al $2006^{13}$. Briefly, ACE activity assays were performed in a Tris $\mathrm{HCl} 100 \mathrm{mM} \mathrm{pH} 7.0$ buffer containing $\mathrm{NaCl} 100 \mathrm{mM}$ and $\mathrm{ZnCl} 2$ $10 \mathrm{mM}$. Lisinopril (Sigma, USA) was used as ACE inhibitor to ensure substrate specificity. The reactions were continuously followed in a Gemini XS fluorimeter (Molecular Devices Company, Sunnyvale, CA, USA) that measured the fluorescence at lex = $320 \mathrm{~nm}$ and lem $=420 \mathrm{~nm}$ (Abz group) and lex $=360 \mathrm{~nm}$ and lem $=440 \mathrm{~nm}$

All measurements were performed in duplicate and proteases activity values were reported as nanomolar of substrate hydrolyzed per minute per milligram of protein $\left(\mathrm{nM} \cdot \mathrm{min}^{-1} \cdot \mathrm{mg}^{-1}\right)$.

\section{Outcome Variables}

The primary outcome variable was ACE activity. Secondary outcome variables were changes in days with headaches, migraine frequency, psychometric scores, and attacks trigger factors.

\section{Statistical Analysis}

Between- and within-groups comparisons (4 groups $\times 2$ times) for ACE activity, anthropometric variables, and psychometric scores were performed by repeated-measure ANOVA with Bonferroni's post hoc corrections for multiple pairwise comparisons. Comparisons between migraine groups ( 2 groups $\times 2$ time points) for clinical variables were performed by repeated-measure ANOVA with Bonferroni's adjustments for multiple pairwise comparisons. Differences between pre-post intervention values (delta values) for proteases activity were calculated by univariate ANOVA with Bonferroni's corrections for pairwise comparisons.

For the trigger factors analyses, we performed descriptive statistics of the trigger's prevalence in the patients' sample. Correlations were calculated by Pearson's correlation coefficients or Spearman's correlation coefficients, depending on variables distribution features. The SPSS software (IBM SPSS Statistics for Windows, Version 20.0. Armonk, NY) was used for statistical analyses. A $p<0.05$ was accepted as statistically significant.

\section{Results}

Fifty-eight participants were randomized, concluded the study, and were per protocol- analyzed. Participants characteristics' are reported in Table 1. For days with migraine and migraine attacks frequency, there were no statistically significant differences between migraine groups at baseline (Table 1). There was a significant group vs time interaction $[F(1,29)=8.921, p=0.006, \eta 2=0.56]$ for days with migraine. Migraine exercise group showed a significant reduction in days with headaches [mean difference $(95 \% \mathrm{Cl})=-5.0$ $(-8.5,-1.4) ; p=0.007]$, without significant changes observed in the migraine waitlist group [mean difference $(95 \% \mathrm{Cl})=2.2(-1.2,5.7)$; $p=0.19)]$. No significant group vs time interaction was observed for migraine attacks frequency $[F(1,29)=1.389, p=0.248, \eta 2=0.06]$.

For plasma ACE activity, repeated-measure ANOVA's pairwise comparisons showed no differences between groups at baseline (Figure 1), while there was a group vs time interaction $[F(3,54)$ $=3.324, p=0.026, \eta 2=0.42]$. Bonferroni-adjusted pairwise comparisons showed increased ACE activity in migraine exercise group compared to control waitlist group after the intervention period [mean difference $(95 \% \mathrm{Cl})=33.8 \mathrm{nM} \cdot \mathrm{min}^{-1} \cdot \mathrm{mg}^{-1}(1.0,66.5)$, $p=0.02]$. One-way ANOVA univariate test using the delta values expressed as percentage change from baseline showed significant between-group effects $[F(3,54)=3.223, p=0.03, \eta 2=0.41]$, with ACE activity in migraine exercise group [mean difference $(95 \% \mathrm{Cl})=$ $47.3 \%(21.3 \%, 75.5 \%)]$ significantly higher than the control waitlist group [mean difference $(95 \% \mathrm{Cl})=-9.1 \%(-41.1 \%, 19.3 \%)$ ]; $p=$ 0.039] (Figure 1). There were no correlations between ACE activity and days with migraine, neither at baseline $(r=-0.83, p=0.657)$ nor for changes after the intervention period $(r=-0.156, p=0.409)$. $p<0.001, \eta 2=0.27]$. Bonferroni-adjusted pairwise comparisons 
Table 1. Participants anthropometric and clinical characteristics. Data are expressed as mean \pm SD

\begin{tabular}{|c|c|c|c|c|}
\hline & \multicolumn{4}{|c|}{ Groups } \\
\hline & Control Waitlist & Control Exercise & Migraine Waitlist & Migraine Exercise \\
\hline Age (yrs) & $35.3 \pm 9.5$ & $34.4 \pm 11.5$ & $36.2 \pm 10.2$ & $39.8 \pm 13.5$ \\
\hline $\mathrm{BMI}\left(\mathrm{kg} / \mathrm{cm}^{2}\right)$ & $26.2 \pm 3.4$ & $25.6 \pm 3.6$ & $26.4 \pm 5.4$ & $27.2 \pm 4.1$ \\
\hline \multicolumn{5}{|l|}{ Sex } \\
\hline Female & 11 & 11 & 12 & 12 \\
\hline Male & 4 & 4 & 3 & 3 \\
\hline \multicolumn{5}{|l|}{ Diagnosis } \\
\hline MwoA & - & - & 7 & 5 \\
\hline MwA & - & - & 4 & 8 \\
\hline $\mathrm{CM}$ & - & - & 4 & 3 \\
\hline Time with Disease (yrs) & - & - & $15.9 \pm 8.9$ & $18.5 \pm 11.9$ \\
\hline Days with Headaches (/month) & - & - & $9.0 \pm 5.9$ & $12.3 \pm 8.0$ \\
\hline Acute Medication (/month) & - & - & $7.4 \pm 6.3$ & $9.4 \pm 9.9$ \\
\hline $\mathrm{SBP}(\mathrm{mmHg})$ & $112.5 \pm 2.8$ & $114 \pm 2.5$ & $110 \pm 2.7$ & $115.6 \pm 2.5$ \\
\hline $\mathrm{DBP}(\mathrm{mmHg})$ & $74.1 \pm 1.7$ & $75 \pm 1.5$ & $69.6 \pm 1.6$ & $72.6 \pm 1.5$ \\
\hline $\mathrm{VO}_{2 \text { Peak }}$ & $34.0 \pm 7.5$ & $33.0 \pm 6.8$ & $31.5 \pm 6.7$ & $31.5 \pm 6.7$ \\
\hline
\end{tabular}

MwoA: Migraine without aura; MwA: Migraine with aura; CM: Chronic migraine; SBP: Sitolic Blood Pressure; DBP: Diatolic Blood Pressure; VO 2 Peak: Peak Oxygen Uptake (Measure of cardiorespiratory fitness).
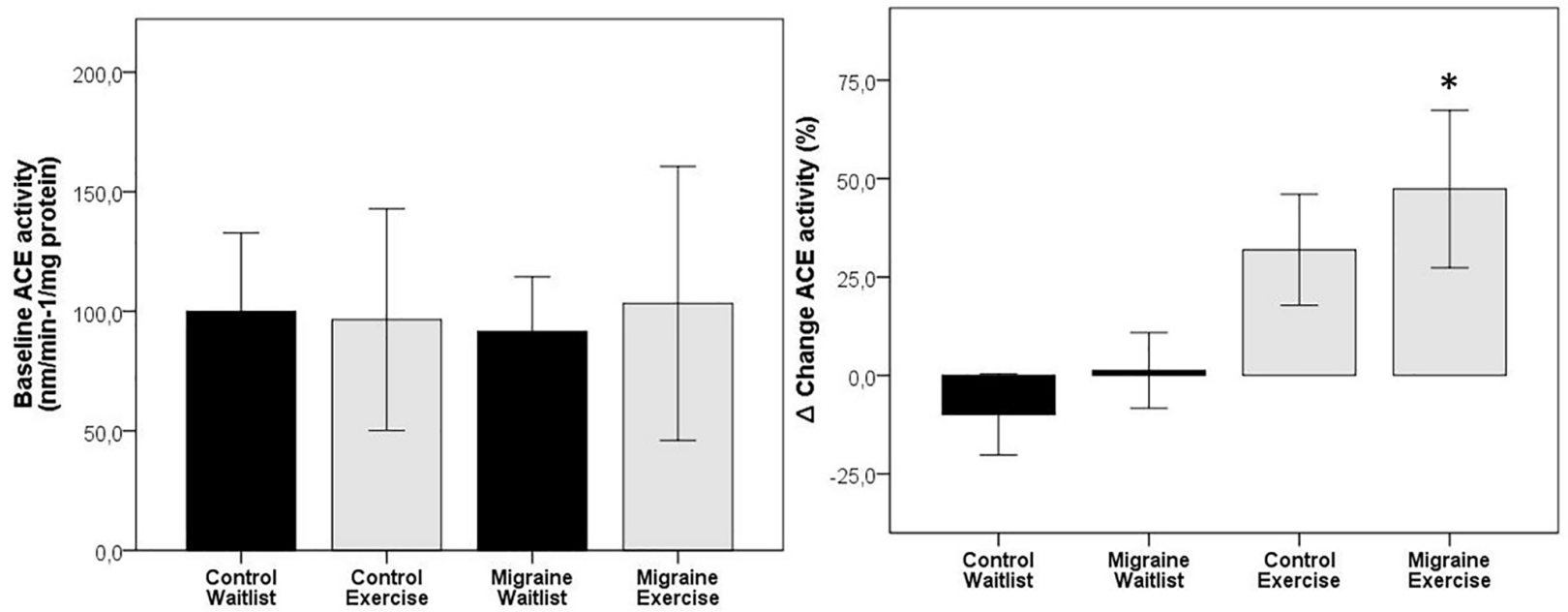

Figure 1. Plasma angiotensin-converting enzyme activity at baseline and percentage change after intervention. Data are expressed as mean \pm SE. ${ }^{*}: p<$ 0.05 , compared with control waitlist

showed that the migraine waitlist group had higher baseline BECKII total score than the control waitlist [mean difference $(95 \% \mathrm{Cl})=$ $11.9(4.6,19.1) ; p<0.001]$, control exercise [mean difference $(95 \%$ $\mathrm{Cl})=12.5(5.7,19.3) ; \mathrm{p}<0.001]$, and migraine exercise [mean difference $(95 \% \mathrm{Cl})=7.0(.56,13.6) ; p=0.027]$ groups (Figure 2). For the BECK-II insomnia domain, repeated-measure ANOVA showed a main effect of time $[F(1,58)=9.444, p=0.003, \eta 2=$ $0.17]$.
Bonferroni-adjusted pairwise comparisons showed that the migraine exercise group had higher baseline BECK-II insomnia score than the control exercise group [mean difference $(95 \% \mathrm{Cl})=0.409$ (0.007, $0.901) ; p<0.001$, and was the only group with significant changes after intervention period [mean difference $(95 \% \mathrm{Cl})=-0.625(-996$, -254), $p=0.001$ ] (Figure 2). No significant main effects of time or group, neither interaction was observed for BECK-II irritability domain. 

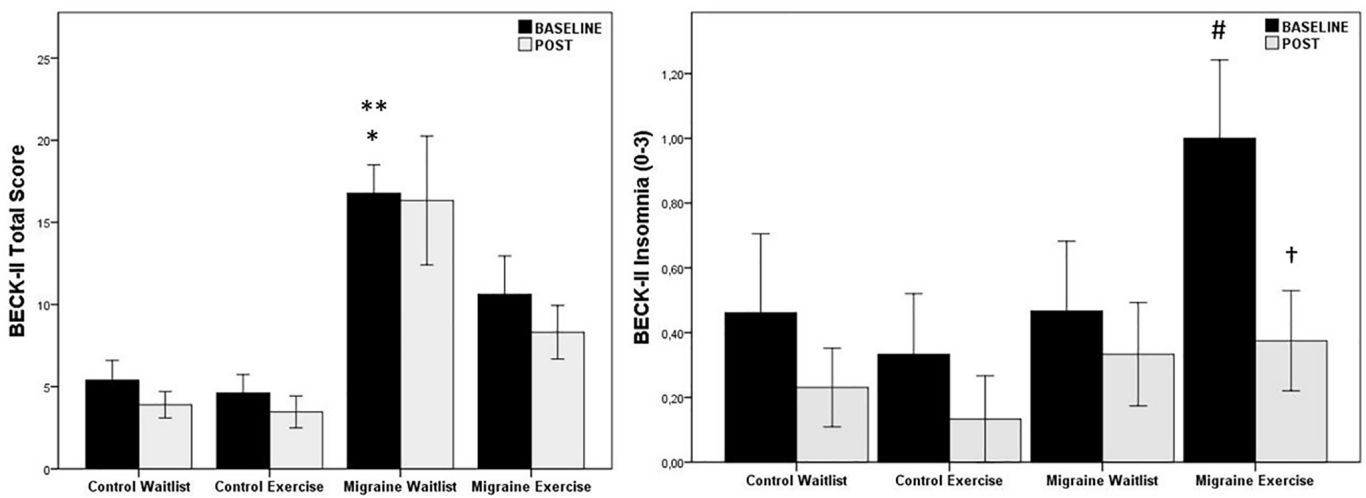

Figure 2. Beck II inventory scores (total and insomnia domain) at baseline and after intervention. Data are expressed as mean \pm SE. *: $p<0.05$, compared with migraine exercise group; ${ }^{* *}: p<0.001$, compared with control exercise and control waitlist groups; \#: $p<0.001$, compared with control exercise group; $\uparrow: p<0.01$, compared with baseline.

Because triggers prevalence varied both within and between subjects over the study period, we only conducted a descriptive analysis of triggers. The most common triggers were stress/ irritability, sleep deprivation, and fasting (Figure 3). The migraine exercise group showed a greater numeric reduction than migraine waitlist group for sleep-deprivation (-21 vs -8 attacks, respectively) and stress/irritability triggers (-20 vs -13 , respectively) (Figure 3 ). In order to explore the relation of major triggers in this sample with ACE activity, we compute the correlations of BECK-II subdomains as potential triggers correlates, that is, the BECK-II insomnia domain for sleep deprivation trigger, and the irritability domain for stress/irritability trigger. There was an inverse correlation between changes (delta values) in BECKII insomnia domain scores and ACE activity $(r=-0.53, p=0.035)$, while there was no correlation between ACE activity and BECK-II irritability domain scores $(r=0.022, p=0.883)$.

\section{Discussion}

This study aimed at measuring the effect of a 12- week supervised moderate aerobic exercise training on plasma ACE activity and whether there would be any correlations with clinical outcomes. To the best of our knowledge, this is the first study to report a stimulatory effect of regular aerobic exercise on plasma ACE activity in migraine patients (nearly 50\% increase), and a correlation between plasma ACE activity and sleep quality scores. Contrary to our hypothesis, we found no baseline ACE activity differences between migraine and control groups.

Clinical studies have found elevated circulating ACE activity in migraine patients in the interictal period ${ }^{3}$ and increased plasma Angll and aldosterone in patients experiencing salt-induced migraine attacks ${ }^{14}$. At molecular level, an immunocytochemical investigation has uncovered the presence of an angiotensinergic system in the trigeminal ganglia of humans and rats ${ }^{5}$, suggesting a role for this signaling system in migraine pathophysiology. At genetic level, a meta-analysis found no association between ACE I/D polymorphism and migraine, albeit in the Turkish population
ACE II polymorphism - which is characterized by lower ACE expression than DD polymorphism - was associated with reduced risk for migraine ${ }^{4}$. Furthermore, ACE inhibitors or Angll receptor antagonists are common prophylactic drugs prescribed for migraine 15,16

As such, we expected that migraine patients would exhibit higher baseline ACE activity that could be reversed by aerobic exercise training with clinical implications, as observed in other pathological conditions such as hypertension ${ }^{17}$, heart failure ${ }^{18}$, or chronic kidney disease $^{6,18}$, wherein there is a noticeable exaggerated RAS activity. Our results indicate that the relationship between ACE and migraine and its response to exercise is not as simplistic as hypothesized. Possible explanations to our data may lie in the etiological mechanisms of migraine, ACE response to exercise, and the complex, less known ACE actions on pain and sleep physiology.

The response of ACE or Angll to exercise vary in the population, with studies showing increase, decrease or no change following either acute or chronic exercise ${ }^{6,7}$. Increased resting, interictal ACE activity in migraine reported in a previous study was interpreted as a compensatory mechanism over vasoactive/algogenic molecules involved in migraine pathophysiology such as nitric oxide (NO) and calcitonin gene-related peptide (CGRP) ${ }^{3}$. In fact, there are evidences corroborating this hypothesis, showing an inhibitory effect of ACE on $\mathrm{NO}^{19}$ and CGRP 20 production. A recent study showed an abnormal cardiovascular response following the administration of the $\mathrm{NO}$ donor nitroglycerin in migraine patients, suggesting heightened sensitivity to $\mathrm{NO}$ in this population ${ }^{21}$. Moreover, aerobic exercise is one of the more effective natural inducers of NO release - which in turn has been also credited as the cause of exerciseprovoked migraine attacks 22 . Thus, theoretically, this higher ACE activity response to exercise training found here could represent a migrainespecific compensatory mechanism to counteract exercise-induced exaggerated $\mathrm{NO}$ actions in migraine patients.

The RAS system has been implicated in pain ${ }^{11,23,24}$ and sleep $^{25}$ physiology. Preclinical and clinical studies suggest a dual action of the RAS in pain perception, partly depending on whether its actions are mediated by angiotensin type-1 (AT1) or type-2 (AT2) receptors ${ }^{1}$. 

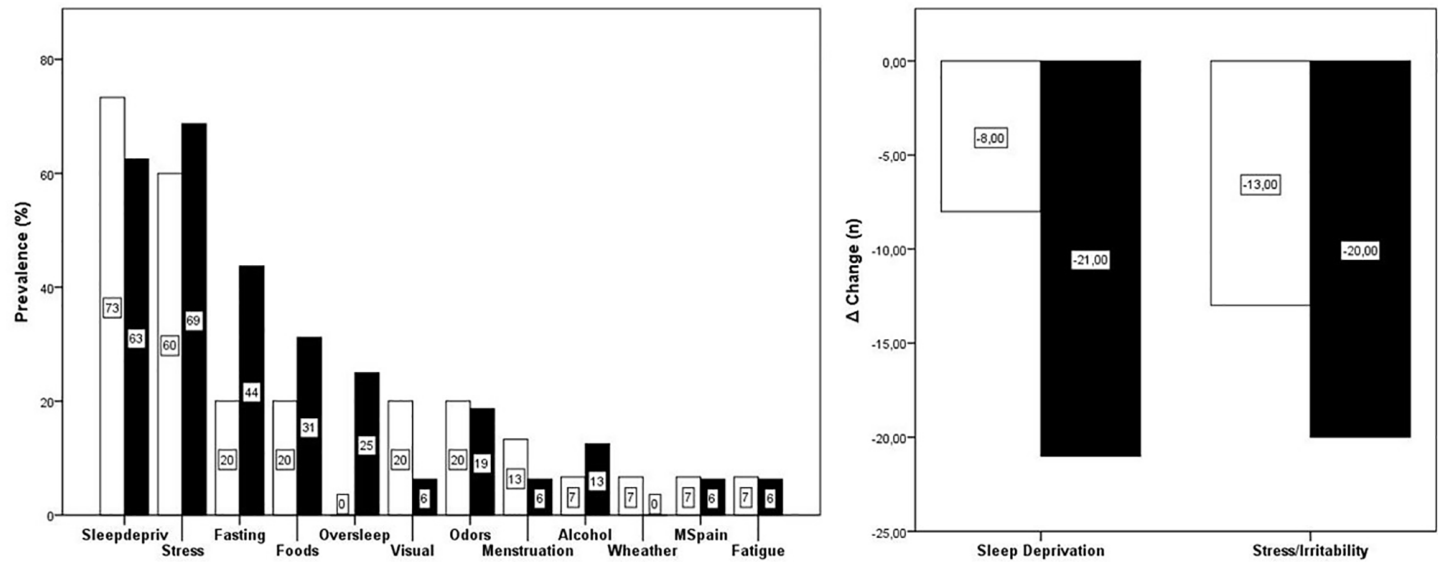

Figure 3.Prevalence of triggers (\%) and changes in the number of trigger-related attacks for sleep and stress/irritability (numeric changes from group's sum).

It seems that through AT1 receptors, ACE-Angll can promote algogenic effects in several models of neuropathic and nociceptive pain by activating downstream signaling cascades culminating in pro-inflammatory cytokines upregulation, such as interleukin-6 (IL-6) and tumor necrosis factor-a (TNF-a) ${ }^{11}$. As pro-inflammatory cytokines are associated with migraine ${ }^{26}$, this could be a putative mechanism through which ACE activity inhibitors or AT1 receptors antagonists are efficacious for migraine prophylaxis ${ }^{11,16}$.

On the other hand, mounting evidence have suggested opposite effects of ACE-Angll on pain through AT2 receptors-dependent and -independent mechanisms centrally and in the periphery" ${ }^{11}$. As reviewed by Bali et al. ${ }^{11}$, microinjections of Anll administered in the ventrolateral periachedutal gray matter (PAG) attenuates nociception in pain paradigms such as tail flick test and incision allodynia; intracerebroventricular administration of Angll promotes increases of tail flick and thermoalgesic stimuli latencies in rats; spontaneous hypertensive rats, which exhibit high RAS tone, have decreased pain sensitivity, while peripheral administration of Anll in normal rats decrease pain sensitivity. A higher RAS tone seems to mediate higher pain tolerance in hypertensive patients, as enalapril and losartan were shown to induce a lower dental pain tolerance in these patients ${ }^{24}$.

The mechanisms by which ACE-Angll exerts hypoalgesic effects is believed to involve its stimulatory action of Angll on $\beta$-endorphin release, the participation of ACE in kinins degradation such as the potent algogenic mediators bradykinin and substace $P$ (besides NO and CGRP aforementioned), and the formation of other peptides derived from Angll with centrally-mediated antinociceptive actions ${ }^{11,23}$.

The correlation between improved insomnia score and changes in ACE activity following exercise training may involve also the interaction between physical exercise and RAS in sleep regulation. Regular aerobic exercise has been associated with improved sleep ${ }^{27}$, and is considered a synchronizer of human circadian rhythms, partly by modulating melatonin secretion ${ }^{28,29}$. The RAS is believed to exerts stimulatory effects on melatonin production? Angiotensin, ACE, Angll, and ATI receptors are present in the pineal gland of rats, and pineal gland forms Angll at a higher rate than other brain areas. Furthermore, oral administration of losartan, an AT1 antagonist, reduces by $35 \%$ the melatonin secretion, while pineal gland cultures treated with this drug yielded a $67.6 \%$ reduction in melatonin secretion in rats ${ }^{25}$. Conversely, reduction in ACE specific activity and mRNA relative levels was observed in the hypothalamus and brainstem of rats under the paradoxal sleep deprivation paradigm ${ }^{30}$.

Considering the prominent role of melatonin in migraine pathophysiology ${ }^{31}$, and its modulation by the RAS9, along with the influence of physical exercise on both hormonal signaling systems $s^{6,7,28,29}$, it is admissible to speculate on a possible causal relation with regard the significant inverse correlation between BECK II insomnia score and plasma ACE activity in migraine patients following aerobic exercise training.

At this point, it is worth mentioning some aspects of ACE biochemistry in the body that should be considered when interpreting the data here. ACE et al. can be found in either plasma soluble or membrane bound forms, with tissue-specific production ${ }^{30}$. As underscored by Visniauskas et al. ${ }^{30}$, as a cytoplasmatic membrane anchored enzyme, ACE turnover may vary in tissues and suffer influence of other peptidases, as well as its catalytic effects may be dissociated from Angll formation. Agreeably, the antihypertensive effects of ACE inhibition have long been seen to fail to correlate with plasma ACE inhibition ${ }^{32}$. Moreover, aerobic exercise can stimulate ACEindependent Angll production ${ }^{33}$. Nonetheless, our data cannot be extrapolated to assume that plasma ACE reflect the actions of ACEAngll on pain and sleep processes in the brain.

The limitations of this study are as follows: this is a post hoc analysis from a clinical trial, therefore, the primary outcome in this analysis was not the original primary outcome. This per-protocol analysis also included 7 chronic migraine patients excluded from primary analysis. Also, the findings here cannot be generalized to the whole migraine population, as the data are underpowered, and the sample's clinical characteristics are different regarding exercisetrigger attacks. For example, the fact that migraine participants showed no exercisetrigger attack, which is commonly observed 
in this population ${ }^{10}$, and voluntarily sought for exercise as a therapeutic option for migraine may constitute selection biases.

In conclusion, this study found a stimulatory effect of regular aerobic exercise on plasma ACE activity in migraine patients, which was inversely correlate with improved insomnia scores. Further studies should explore the participation of the RAS, and the relation of other ACE-derived peptides following exercise in migraine patients in a larger cohort. Clinical aspects of migraine such as trigger profile and its relationship with these molecules could also provide insights for the participation of RAS in multiple behavioral and homeostatic features of migraine.

Aknowlegements: The authors appreciate the whole staff of the Center for Studies in Psychobiology and Exercise for their support in scheduling and conducting the exercise sessions and testing

\section{References}

1. Peres M, Mercante J, Belitardo de Oliveira A. Non-Pharmacological Treatment for Primary Headaches Prevention and Lifestyle Changes in a Low-Income Community of Brazil: A Randomized Clinical Trial. Headache: The Journal of Head and Face Pain. 2019;59(1):86-96.

2. Oliveira AB, Ribeiro RT, Mello MT, Tufik S, Peres MFP. Anandamide Is Related to Clinical and Cardiorespiratory Benefits of Aerobic Exercise Training in Migraine Patients: A Randomized Controlled Clinical Trial. Cannabis and Cannabinoid Research. 2019;4(4):275-84.

3. Fusayasu E, Kowa H, Takeshima T, Nakaso K, Nakashima K. Increased plasma substance P and CGRP levels, and high ACE activity in migraineurs during headache-free periods. Pain. 2007;128(3):209-14.

4. Wan D, Wang C, Zhang X, Tang W, Chen M, Dong Z, et al. Association between angiotensin- converting enzyme insertion/deletion polymorphism and migraine: a meta-analysis. International Journal of Neuroscience. 2016;126(5):393-9.

5. Imboden A, Patil J, Nussberger J, Nicoud F, Hess B, Ahmed $\mathrm{N}$, et al. Endogenous angiotensinergic system in neurons of rat and human trigeminal ganglia. Regul Pept. 2009;154(13):23-31.

6. Goessler K, Polito M, Cornelissen V. Effect of exercise training on the renin-angiotensin- aldosterone system in healthy individuals: a systematic review and meta-analysis. Hypertension research : official journal of the Japanese Society of Hypertension. 2016:39(3):119-26.

7. Rush J, Aultman C. Vascular biology of angiotensin and the impact of physical activity. Appl Physiol Nutr Metab [Internet]. 2008;33(1):162-72.

8. Müller H, Kröger J, Jöhren O, Szymczak S, Bader M, Dominiak $P$, et al. Stress sensitivity is increased in transgenic rats with low brain angiotensinogen. Journal of Endocrinology. 2010;204(1):85-92.

9. Campos LA, Cipolla-neto J, Amaral FG, Michelini LC, Bader M, Baltatu OC. The Angiotensin- Melatonin Axis. International Journal of Hypertension. 2013;2013:1-7.

10. Pellegrino ABW, Davis-Martin RE, Houle TT, Turner DP, Smitherman TA. Perceived triggers of primary headache disorders: A meta-analysis. Cephalalgia. 2017;38(6):1188-98.

11. Bali A, Singh N, Jaggi A. Renin-angiotensin system in pain: existing in a double life? J Renin Angiotensin Aldosterone Syst. 2014;15(4):329-40.
12. Headache Classification Sub-Committee of the International Headache Society. The International Classification of Headache Disorders. Cephalagia, 2004, 24:9-160.

13. Carmona A, Schwager S, Juliano M, Juliano L, Sturrock E. A continuous fluorescence resonance energy transfer angiotensin I-converting enzyme assay. Nature Protocols. 2006;1(4):1971-6.

14. Brainard J. Angiotensin and Aldosterone Elevation in Saltinduced Migraine. Headache: The Journal of Head and Face Pain. 1981;21(5):222-6.

15. Silberstein SD, Holland S, Freitag F, Dodick DW, Argoff C, Ashman E. Evidence-based guideline update: pharmacologic treatment for episodic migraine prevention in adults: report of the Quality Standards Subcommittee of the American Academy of Neurology and the American Headache Society. Neurology [Internet]. 2012;78(17):1337-45.

16. Tronvik E, Stovner LJ, Helde G, Sand T, Bovim G. Prophylactic Treatment of Migraine With an Angiotensin II Receptor Blocker. JAMA. 2003 Jan 1;289(1):65-9.

17. Ghiadoni L, Taddei S, Virdis A. Hypertension and Endothelial Dysfunction: Therapeutic Approach. Current Vascular Pharmacology. 2011;10(1):42-60.

18. Haack K, Zucker I. Central Mechanisms for Exercise TrainingInduced Reduction in Sympatho- Excitation in Chronic Heart Failure. Autonomic Neuroscience [Internet]. 2015;0:44-50.

19. Ancion A, Tridetti J, Nguyen Trung M-L, Oury C, Lancellotti P. A Review of the Role of Bradykinin and Nitric Oxide in the Cardioprotective Action of Angiotensin-Converting Enzyme Inhibitors: Focus on Perindopril. Cardiology and Therapy. 2019:8(2):179-91.

20. Krämer HH, Schmidt K, Leis S, Schmelz M, Sommer C, Birklein F. Angiotensin converting enzyme has an inhibitory role in CGRP metabolism in human skin. Peptides. 2006;27(4):917- 20.

21. van Oosterhout WPJ, Schoonman GG, Saal DP, Thiij RD, Ferrari $M D$, van Dijk JG. Abnormal cardiovascular response to nitroglycerin in migraine. Cephalalgia [Internet]. 2019;0(0):1-12.

22. Hindiyeh NA, Krusz JC, Cowan RP. Does Exercise Make Migraines Worse and Tension Type Headaches Better? Curr Pain Headache Rep. 2013;17:380.

23. Pelegrini-da-Silva A, Rosa E, Guethe LM, Juliano MA, Prado WA, Martins AR. Angiotensin III modulates the nociceptive control mediated by the periaqueductal gray matter. Neuroscience [Internet]. 2009;164(3):1263-73.

24. Guasti L, Zanotta D, Diolisi A, Garganico D, Simoni C, Gaudio $G$, et al. Changes in pain perception during treatment with angiotensin converting enzyme-inhibitors and angiotensin II type 1 receptor blockade. Journal of Hypertension. 2002;20(3):485-91.

25. Baltatu O, Afeche SC, José dos Santos SH, Campos LA, Barbosa $\mathrm{R}$, Michelini LC, et al. Locally synthesized angiotensin modulates pineal melatonin generation. Journal of neurochemistry [Internet]. 2002 Jan;80(2):328-34.

26. Oliveira AB, Bachi ALL, Ribeiro RT, Mello MT, Tufik S, Peres MFP. Unbalanced plasma TNF-a and IL-12/IL-10 profile in women with migraine is associated with psychological and physiological outcomes. Journal of Neuroimmunology. 2017;313:138-44.

27. Rubio-Arias JÁ, Marín-Cascales E, Ramos-Campo DJ, Hernan$\operatorname{dez} A$ v., Pérez-López FR. Effect of exercise on sleep quality and insomnia in middle-aged women: A systematic review and meta- analysis of randomized controlled trials. Maturitas. 2017;100:49-56.

28. Knight J a, Thompson S, Raboud JM, Hoffman BR. Light andexercise and melatonin production in women. American journal of epidemiology. 2005;162(11):1114-22.

29. Buxton OM, Lee CW, L'Hermite-Baleriaux M, Turek FW, van Cauter E. Exercise elicits phase shifts and acute alterations of melatonin that vary with circadian phase. American journal of 
physiology Regulatory, integrative and comparative physiology [Internet]. 2003 Mar [cited 2014 Mar 19];284(3):R714-24.

30. Visniauskas B, Oliveira V, Carmona A, D'Almeida V, de Melo $R$, Tufik $S$, et al. Angiotensin I- converting enzyme (ACE) activity and expression in rat central nervous system after sleep deprivation. Biol Chem. 2011;392(6):547-53.

31. Peres MF, Valença MM, Amaral FG, Cipolla-Neto J. Current understanding of pineal gland structure and function in headache. Cephalalgia. 2019;0(0):1-10.
32. Waeber B, Nussberger J, Juillerat L, Brunner HR. Angiotensin converting enzyme inhibition: discrepancy between antihypertensive effect and suppression of enzyme activity. Journal of Cardiovascular Pharmacology. 1989;14(Suppl 4):S53-9.

33. Aldigier JC, Huang H, Dalmay F, Lartigue M, Baussant $T$, Chassain, A. P., Leroux-Robert C, et al. Angiotensin-Converting Enzyme Inhibition Does Not Supress PLasma Angiotensin II Increase During Exercise in Humans. Journal of Cardiovascular Pharmacology. 1993;21:289-95. 